\title{
Erratum to: The impact of repetitive navigated transcranial magnetic stimulation coil positioning and stimulation parameters on human language function
}

Nico Sollmann ${ }^{1,2}$, Sebastian Ille ${ }^{1,2}$, Thomas Obermueller ${ }^{1,2}$, Chiara Negwer $^{1,2}$,

Florian Ringel ${ }^{1,2}$, Bernhard Meyer $^{1}$ and Sandro M Krieg ${ }^{1,2^{*}}$

\section{Erratum to: European Journal of Medical Research (2015) 20:47 \\ DOI 10.1186/s40001-015-0138-0}

Following publication of our article [1], it was noticed that an error to the presentation of Table 2 was introduced by the publisher. The corrected table is given below (Table 1) and has been updated in the original publication [1].

\section{Reference}

1. Sollmann N, Ille S, Obermueller T, Negwer C, Ringel F, Meyer B et al (2015) The impact of repetitive navigated transcranial magnetic stimulation coil positioning and stimulation parameters on human language function. Euro J Med Res 20:47

Table 1 Summary of stimulation parameters and coil angulations

\begin{tabular}{|c|c|c|c|c|c|c|c|c|c|c|c|c|}
\hline \multirow[t]{2}{*}{ Subject } & & \multicolumn{5}{|c|}{ Broca } & \multicolumn{5}{|c|}{ Wernicke } & \multirow{2}{*}{$\begin{array}{l}\mathbf{p} \\
-\end{array}$} \\
\hline & & $\# 1$ & \#2 & \#3 & $\# 4$ & \#5 & $\# 1$ & \#2 & \#3 & $\# 4$ & \#5 & \\
\hline \multirow[t]{2}{*}{ Optimal coil angulation (in ${ }^{\circ}$ ) } & To ap orientation & 225 & 90 & 90 & 135 & 90 & 90 & 45 & 180 & 270 & 135 & 0.8288 \\
\hline & To reference gyrus & 135 & 0 & 0 & 45 & 0 & 0 & 315 & 90 & 180 & 45 & 0.1945 \\
\hline \multicolumn{2}{|c|}{ Optimal stimulation frequency (in $\mathrm{Hz}$ ) } & 10 & 10 & 20 & 20 & 7 & 20 & 20 & 20 & 7 & 10 & 0.7337 \\
\hline \multicolumn{2}{|c|}{ Optimal stimulation intensity (\% RMT) } & 100 & 120 & 120 & 120 & 100 & 120 & 100 & 100 & 120 & 120 & 0.9025 \\
\hline \multicolumn{2}{|c|}{ Electrical field strength (in V/m) } & 85 & 120 & 95 & 100 & 70 & 95 & 75 & 105 & 90 & 75 & 0.7526 \\
\hline
\end{tabular}

Author details

${ }^{1}$ Department of Neurosurgery, Klinikum rechts der Isar, Technische Universität

München, Ismaninger Str. 22, 81675 Munich, Germany. ${ }^{2}$ TUM-Neuroimaging

Center, Klinikum rechts der Isar, Technische Universität München, Ismaninger

Str. 22, 81675 Munich, Germany.

The online version of the original article can be found under

doi:10.1186/s40001-015-0138-0.

Received: 21 July 2015 Accepted: 21 July 2015

Published online: 02 September 2015

\footnotetext{
*Correspondence: Sandro.Krieg@|rz.tum.de

${ }^{1}$ Department of Neurosurgery, Klinikum rechts der Isar, Technische

Universität München, Ismaninger Str. 22, 81675 Munich, Germany

Full list of author information is available at the end of the article
} provided you give appropriate credit to the original author(s) and the source, provide a link to the Creative Commons license, and indicate if changes were made. The Creative Commons Public Domain Dedication waiver (http://creativecommons.org/ publicdomain/zero/1.0/) applies to the data made available in this article, unless otherwise stated. 